Fecha de recepción: octubre 2019

Fecha de aceptación: diciembre 2019

Versión final: diciembre 2021

\section{A través del ojo colonial. Discursos visuales de la mujer indígena boliviana}

Alejandra Guardia Manzur ${ }^{1}$

Resumen: El presente artículo abordará el diseño del discurso visual de las fotografías publicadas en el libro Mujer indígena en la ciudad realizado por el Centro de Documentación e Información de Bolivia. El objetivo es analizar el discurso sobre la mujer indígena y su rol en la ciudad; es decir cómo la sociedad ha diseñado un discurso visual que representa la identidad de la mujer indígena con características coloniales. Es pues, a través de estas fotografías que se puede comprender el enraizamiento del imaginario y la visión colonial en las sociedades que han sido conquistadas y que guardan en su mirada los modos de identificar y definir al otro.

Palabras clave: Discurso visual - Diseño de imagen - Identidad - Alteridad - Otro.

[Resúmenes en inglés y portugués en la página 154]

(1) Alejandra Guardia Manzur: Licenciada en Ciencias de la Comunicación Social (Universidad Católica Boliviana San Pablo). Máster en Gestión de Diseño -Universidad de Palermo, en defensa de tesis-. Trabajo de investigación y publicación: Discursos y prácticas de exclusión en los jóvenes de Élite cochabambina a partir del 11 de enero de 2007 -Punto Cero, Revista de Ciencias de la Comunicación de la Universidad Católica Boliviana, disponible en scielo.org-. Mail: ale.guardia@gmail.com

\title{
Introducción
}

El concepto de discurso por lo general está ligado al lenguaje escrito o hablado, sin embargo, existen discursos y mensajes intrínsecos al diseño de una imagen, haciendo de estas -las imágenes-, un documento social importante que trae consigo relatos y modos de mirar y ser mirado. En este sentido, el discurso visual, supone un mensaje, una mirada de cierto momento y contexto a partir del cual surge $y$, por supuesto, determina el modo de construir un referente de identidad que define la mirada sobre una sociedad que por entero es diversa.

Estos modos de construir realidades sociales están enraizados a un momento determinante de la historia latinoamericana, la época colonial, que ha marcado el imaginario social, 
cultural y económico de una sociedad completamente diferente a la del conquistador y que, sin embargo, ha ido adoptando el quehacer del actor de dominación.

Es por esto que, dentro de la sociedad, se pueden encontrar rasgos europeizantes en las identidades forjadas por un pasado claramente oscuro y de dominación que, lejos de ser negados, se adoptan fervientemente en distintos procesos culturales con vistas a una sociedad en progreso y modernización. Esto, resulta de un pensamiento xenófilo a partir del cual determinada sociedad se siente culturalmente inferior por lo que aspira lograr los valores occidentales que han descubierto (Todorov, 1990).

Dentro de este intento de apropiación constante, se producen los quiebres culturales a partir de los cuales se evidencian las luchas de clases y la negación del otro. Entonces, se produce una dialéctica de la negación que, en un primer momento, el colonizador o el blanco se diferencia del otro para desvalorizarlo en tanto sujeto ignorante y retrasado del progreso determinado por la voz dominante (Hopenhayn, 1999).

El otro (indio, autóctono, no occidental) es el sujeto en que se realiza el rito: la realidad mágica, el folklore, el saber precientífico, la expresividad espontánea y el arte local. El logos (como dominio de la razón, del discurso "verdadero", de la ciencia y del desarrollo) es el dominio del "blanco", del occidental, en suma, la voz del progreso (Hopenhayn, 1999, p. 78).

Por consiguiente, las imágenes permiten entender ciertos comportamientos del acontecer social y este discurso es el que establece la realidad misma de esa sociedad. Es decir, "no 'vemos' simplemente lo que está allí ante nosotros. Más bien las formas específicas como vemos -y representamos-, el mundo determina cómo es que actuamos frente a éste y, al hacerlo, creamos lo que ese mundo es" (Poole, 2000, p. 15).

Entonces, la fotografía contiene una carga representativa social e histórica que expresa las intenciones del autor, pero más importante aún, el esquema de percepción y pensamiento de un grupo y, por lo tanto, entender la carga de significados que contiene permite revelar lo simbólico de una época y clase social (Bourdieu, 2003).

En este sentido, el presente artículo pretende desentrañar aquellos discursos expuestos en imágenes diseñadas para el Concurso Nacional de Fotografía "Mujer indígena en la ciudad” (2009) organizado por el Centro de Investigación e Información Bolivia -en adelante CEDIB-. Las imágenes de este concurso fueron publicadas en un catálogo compuesto por 12 categorías y 99 fotografías.

El CEDIB es una organización sin fines de lucro que se ha dedicado a la recolección de información y documentación desde 1970 en Bolivia. Su principal propuesta es la mirada crítica sobre los hechos sociales y culturales del país. Es decir, claramente no pertenece a una mirada gubernamental o política anclada en el poder de turno, sino más bien opera de manera independiente al gobierno y por lo tanto no está mediada por el imaginario de quien encabeza el Estado.

Sin embargo, es justamente este hecho que resulta importante en tanto análisis y discusión, porque pese a la mirada crítica que propone al quehacer social, cultural y económico del país, podría resultar en lo contrario. Y es que, las imágenes, que pertenecen a varios 
autores participantes del concurso, mantienen el esquema de percepción de una organización social heredada.

El análisis de estas imágenes, permite dar cuenta de la constante construcción de un otro como referente de las diferencias sociales y culturales. Es decir, se ha construido una alteridad para establecer la diferencia y es pues que,

El 'otro' [...] no existe ontológicamente. Es una invención discursiva. [...] Tal invención es el resultado de un enunciado que no nombra una entidad existente, sino que la inventa. El enunciado necesita un (agente) enunciador y una institución (no cualquiera puede inventar el anthropos); pero para imponer el anthropos como 'el otro' en el imaginario colectivo se necesita estar en posición de gestionar el discurso (verbal o visual) por el cual se nombra y se describe una entidad (el anthropos o 'el otro') y lograr hacer creer que ésta existe (Mignolo, 2013, p. 12).

Esta invención discursiva -el otro-, se ha establecido en el imaginario colectivo de la sociedad boliviana a modo de crear la brecha entre ciertas clases sociales. En este caso, el otro, el indígena, representa todo aquello que el dominante no es y por lo tanto, ha sido subordinado por éste. Sin embargo, las imágenes analizadas pretenden justamente visibilizar esta identidad opacada por el pasado colonial pero al hacerlo, representan discursos dominantes todavía instaurados en la sociedad puesto que el imaginario y el ojo con el que se diseña la imagen están atravesados aún por los modos de organización y poder colonial. La imagen como elemento discursivo, tiene la capacidad de vislumbrar la lucha simbólica inherente a los modos de organización social anclados en pensamientos eurocéntricos y heredados.

\section{Breve recorrido contextual}

El análisis fotográfico como elemento y fuente comunicacional, como objeto a partir del cual se pueden leer mensajes supone una mirada analítica. En efecto, puede ser abordada como una huella de un rea, tal como propone Dubois (1986).

En este sentido, la fotografía, que es la huella de un real, a decir de Barthes, "jamás se distingue de su referente (de lo que ella representa), [por el contrario], lleva su referente siempre consigo" (2006, p. 30-31).

Este referente de lo real, el cual se analiza en el presente artículo, surge de la idea de que una fotografía es un objeto en un contexto, por tanto se realiza la lectura fotográfica como mensaje o discurso. Es decir, la imagen cargada de sentido para la interpretación y decodificación a partir de diversas condiciones de producción de las cuales surge.

A decir de Verón (1993),

La teoría de los discursos sociales es un conjunto de hipótesis sobre los modos de funcionamiento de la semiosis social [que es entendida como] (...) la 
dimensión significante de los fenómenos sociales: el estudio de la semiosis es el estudio de los fenómenos sociales en tanto procesos de producción de sentido. (...) Toda producción de sentido es necesariamente social: no se puede describir ni explicar satisfactoriamente un proceso significante, sin explicar sus condiciones sociales productivas. [ $\mathrm{Y}$ al mismo tiempo], todo fenómeno social es (...) un proceso de producción de sentido, cualquiera que fuere el nivel de análisis (más o menos micro o macrosociológico) (p. 125, las cursivas del autor).

Es por esta razón que, analizar y entender el contexto en la cual fueron producidas las fotografías, contribuye al entendimiento y análisis del discurso que proponen, es decir, la significación o la idea representada.

El objetivo de este artículo no es brindar una historiografía boliviana, sino más bien dar cuenta del imaginario colectivo que ha surgido a partir de ciertos momentos definitivos, acontecimientos trascendentales y sucesos que han forjado de una u otra manera los modos de construcción y representación social. Es decir, lo que importa es entender el cómo se han forjado las miradas coloniales que definen los modos de representar la identidad del otro.

En este sentido, se pretende describir brevemente aspectos significativos del contexto boliviano a partir del cual surgen las fotografías, como representación de un imaginario que atraviesa el ojo de los autores.

Por consiguiente, no está demás decir que la historia de Bolivia concuerda con muchos de los países latinoamericanos, enmarcados por un pasado colonial que surge del poder hegemónico eurocéntrico, en tanto se ha quebrantado el quehacer cultural, político, social y económico de toda la región que, posteriormente, se enmarcaría dentro de esta misma lógica.

En efecto, esta lógica será puesta en práctica en el país durante los dos siglos posteriores a la fecha de su independencia en 1825 y es pues que, pese a todo el proceso de liberación, es posible apreciar todavía aquellos rasgos coloniales en la organización del Estado-nación. A partir del momento colonial se establecen diferencias culturales y sociales, posterior a éste. Surge un nuevo estatus organizativo que determina como minorías y grupos subordinados a los indígenas del país. Surge el colonialismo interno, concepto ligado a

(...) fenómenos de conquista, en que las poblaciones de nativos no son exterminadas y forman parte, primero, del Estado colonizador y, después, del Estado que adquiere una independencia formal, o que inicia un proceso de liberación, de transición al socialismo o de recolonización y regreso al capitalismo neoliberal. Los pueblos, minorías o naciones colonizados por el Estado-nación sufren condiciones semejantes a las que los caracterizan en el colonialismo y el neocolonialismo a nivel internacional (Gonzáles Casanova, 2003, p. 3).

La organización social se rige a partir de los modos de diferenciación coloniales que distinguen al otro bajo la forma del indígena. Se establece la división de clases a partir del origen étnico y color de piel de las personas, una lucha simbólica contradictoria en un país donde las raíces indígenas y mestizas son predominantes. Cabe recalcar que, esta catego- 
ría -la de indígena o indio-, surge de un discurso hegemónico colonial para establecer la diferencia entre el colonizador y el colonizado (Bonfil, 1972). En este sentido, ser indígena no denota ninguna característica cultural y social de esta identidad, por el contrario, define a un grupo social enteramente diverso y lo unifica bajo la forma de indio. "No importa cuán diferentes sean entre sí los colonizados, lo que verdaderamente importa es que sean diferentes del colonizador. Por eso son indios, genéricamente" (Bonfil, 1972, p. 113). Ahora bien, durante mucho tiempo este fue el modo de organización social y político del país, pues la independencia solamente,

(...) implicó un cambio de actores en la alta jerarquía estatal y una nueva forma de administración de los recursos, no significó una transformación en el sistema de relaciones entre el Estado y la sociedad, ya que simplemente tendió a la reproducción de viejas prácticas de sometimiento y explotación a la población local en función de las lógicas del desarrollo del capital y de la nueva élite criollo mestiza (Zegada, 2012, p. 13-14).

La hegemonía de las élites descendientes de europeos fue forjada en base a la diferenciación y clasificación social y el poderío económico por medio de la subordinación de los pueblos indígenas. La organización sociopolítica de Bolivia fue afianzándose de esta manera, el poder político y económico se limitaba a las élites criollas que de una u otra forma se había adaptado al sistema capitalista occidental y por lo tanto, rechazaban la cultura e identidad de la que alguna vez fueron parte.

Esporádicamente surgían demandas indígenas aisladas temporal y territorialmente. Desde fines del siglo XVIII con la rebelión social de Amaru y Katari, hasta 1994 con los intelectuales aymaras que lograron el reconocimiento de la diversidad con las categorías multiétnico y pluricultural expuestos en la Constitución Política del Estado. Por primera vez se reconoce los derechos y costumbres de los pueblos indígenas, siempre cuando el quehacer de los mismos no se interponga a las leyes y Constitución nacional (Rivera Cusicanqui, 2010a, Zegada, 2012).

Este empero dentro de la Constitución, es a lo que Rivera Cusicanqui (2010b) denomina como inclusión condicionada que simula reconocer a los pueblos indígenas en su condición de originarios, reproduciendo claramente los modos de poder colonial al otorgar en primera instancia, el reconocimiento anclado en el origen racial y territorial del sujeto, y por otro lado, al hacerlo, su inclusión está sujeta a una ciudadanía recortada y de segunda clase.

(...) los derechos del indio sólo se reconocen cuando deja de ser indio y asume los rasgos del ciudadano occidental: propietario, escolarizado, mestizo, productor y consumidor mercantil, etc. Todo extremo de violencia y de negación es tolerable en el espacio pre-social del mundo indio, mientras no se cumpla este proceso de ciudadanía forzada como imposición del modelo civilizatorio occidental (Rivera Cusicanqui, 2010a, p. 58, las cursivas de la autora).

Sin embargo, a principios del año 2006, la organización política y ejecutiva del país se reestructura gracias al ingreso, con mayoría absoluta de votos, del primer presidente indígena, 
Evo Morales Ayma. Este cambio estructural en el ámbito sociopolítico, permite no sólo visibilizar las demandas de los pueblos indígenas, sino que logra un espacio discursivo en el cual por primera vez y de manera oficial, estas identidades son escuchadas y representadas legítimamente.

Hasta este momento, las luchas y discursos indígenas habían sido silenciadas por el poder político y económico de las clases dominantes, por lo que los subalternos no tenían voz para hacerse escuchar (Spivak, 2011).

Asimismo, se reestructuró la organización social del país, los espacios públicos y políticos permitieron el reencuentro de las clases sociales para establecer el imaginario de igualdad. Sin embargo, la realidad surgió de manera diferente, las élites se vieron expuestas a un poder político que no los representaba y la lucha simbólica de poder y estatus social continuaba su trayectoria durante los siguientes años de mandato de Morales.

Pese a esto, existieron cambios importantes en el país, pues ya no sólo se establecía el reconocimiento de los pueblos indígenas sino que su participación fue extendiéndose hacia todos los ámbitos de la sociedad. Después de mucho tiempo el subalterno pudo formar parte de los estratos políticos, económicos, sociales y culturales más altos de Bolivia.

Este hecho, sin embargo, no significa la modificación del imaginario social de todo el país, y por lo tanto, los modos de ver y representar estas identidades reflejan el abigarramiento a la estructura y el habitus colonial heredado.

\section{El contexto para la mujer indígena}

Como se ha podido ver hasta el momento, hasta cierto punto de la historia, el rol del indígena dentro de la sociedad boliviana estaba limitado y estructurado por las lógicas coloniales, por lo tanto era considerado sujeto subalterno.

Ahora bien, la mujer indígena, por su parte, sufre una doble subordinación gracias al pensamiento occidental. Por un lado, está sujeta a la categoría de indio representando la figura del otro tradicional y atrasado, y por otro lado, la figura de mujer nace con la colonización como una identidad frágil sujeta al dominio del varón, trabajadora el hogar, no productiva.

Esta doble subordinación tornó la lucha por la igualdad social mucho más compleja, puesto que quedaba supeditada a la revalorización de lo indígena. No es hasta 1952, por ejemplo, que tanto indios y mujeres -en general-, son reconocidos dentro del estrato político con el voto universal y sin embargo, se hace referencia nuevamente a la ciudadanía restringida mencionada anteriormente.

Este sistema de pensamiento desigual entre lo femenino y lo masculino surge por la occidentalización del imaginario colectivo boliviano que se sumergió rápidamente al sistema patriarcal, al catolicismo y a la retórica de la diferencia.

Contrariamente, el sistema de relaciones andinas precolombinas, suponía más bien un reconocimiento y relación bilateral entre ambos géneros, es decir, existía la diferencia pero era aceptada y adaptada a las reglas y quehaceres de las comunidades. El rol de la mujer dentro de los grupos indígenas era importante, en tanto por ejemplo, heredaba el conjun- 
to de bienes a diferencia del hombre, no fueron segregadas y formaban parte importante de la producción y opinión pública, conservando siempre un espacio de poder dentro de la comunidad (Rivera Cusicanqui, 2010a).

Esta forma de relación bilateral se fue quebrantando con la modernidad envuelta en el pensamiento patriarcal sustentado en leyes y discursos legitimados por el poder político de la sociedad.

Es en el momento en que el indígena se tiene que adaptar al poder colono, cuando la mujer indígena o mestiza inicia el proceso de reconfiguración de su identidad, "al cambiar la vestimenta indígena y adoptar la pollera y el mantón españoles, están creando, sin saberlo, los rasgos de identificación que posteriormente -a partir del siglo XVIII-, distinguirán a la 'chola' de los demás sectores de la sociedad urbana" (Rivera Cusicanqui, 2010a, p. 75, las cursivas de la autora).

Actualmente, esta vestimenta "se ha convertido en emblema de una etnicidad discriminada y excluida, que niega y afirma ambiguamente las diferencias de gesto y de conducta, pero las enmascara también en aspiraciones y autopercepciones 'mestizas' o de 'clase media” (Rivera Cusicanqui, 2010a, p. 216).

Ahora bien, mientras más se fue legitimando el poder patriarcal y discriminatorio contra las mujeres, mayor fue la carga negativa por sobre la mujer indígena que fue perdiendo poder dentro de sus propias comunidades.

Su participación en los espacios públicos fue disminuyendo paulatinamente, forjándose los sindicatos y organismos políticos como un acto masculino. Este hecho relegó a la mujer al ámbito comercial para sustentar las actividades políticas de los hombres, que paradójicamente, le fue transfiriendo a la mujer el rechazo y la vergüenza del atraso rural (Rivera Cusicanqui, 2010b).

No es hasta 1990 que surgen los pequeños logros respecto a la inequidad de género, permitiendo en 1994 la elevación a rango de ley de la Convención sobre la Eliminación de Todas las Formas de Discriminación contra la Mujer (Zegada, 2012). Sin embargo, la participación política de la mujer era casi nula, forzando a generar movimientos y luchas para conseguir la igualdad.

Tanto leyes y normas constituidas hasta fines del siglo XX, pese al reconocimiento de los derechos de la mujer, estaban adscritas en un discurso patriarcal, es decir, mantenían su redacción y lenguaje anclado en la masculinidad y la diferencia entre géneros.

Posteriormente, con el gobierno de Evo Morales, se modificaría la Constitución para incluir explícita y discursivamente a la mujer como actor importante de la sociedad y su reconocimiento e igualdad de condiciones con respecto a su participación política, laboral y económica.

Sin embargo, el discurso dista de la realidad actual boliviana, pues la participación de la mujer en cargos políticos por ejemplo, supone un porcentaje casi nulo en comparación con la del hombre.

Por otro lado, la participación de la mujer indígena sigue el mismo camino, pues si bien su inserción al espacio laboral ha sido considerablemente mayor gracias al proceso de cambio político y social, la función que ocupa dentro del mismo se da en un porcentaje sumamente reducido en tanto a posiciones que supongan una real toma de decisiones y discursividad respecto al quehacer sociopolítico. 
En definitiva, la participación de la mujer indígena dentro de la concepción de ciudad -o ciudadano-, aún en la actualidad sufre de la esteotipación doble en tanto cuerpo femenino y cuerpo indígena. Es decir, la mujer discursivamente ha sido encasillada dentro del modelo occidental como ama de casa, comerciante o vendedora, secretaria o asistente, carente de opinión pública y discursiva, sujeto pasivo subordinado ante el poder colonial interno en primera instancia, $y$ en segunda, ante la mirada patriarcal y masculinizadora de la sociedad.

\section{Mujer indígena en la ciudad: sobre el concurso de fotografía}

Como se mencionó anteriormente, la publicación "Mujer indígena en la ciudad” realizada por el CEDIB, contiene fotografías de varios autores que representan a esta identidad en un intento de revalorización.

La organización pretende mantener una mirada crítica sobre los hechos sociales y culturales de Bolivia y esta publicación surge a modo de visualización de justamente esta doble subordinación por la cual atraviesan las mujeres indígenas bolivianas.

En el libro, se encuentra la siguiente presentación:

Ser indígena, mujer y pobre son tres ingredientes de sabor amargo que caracterizan a quienes ocupan la base de la pirámide social en Latinoamérica. Esto es bien conocido, de lo que se habla poco es de los espacios donde estos elementos se articulan o mejor dicho, los espacios donde tienen mayor relevancia ser depositario de estas tres características. Desde nuestro punto de vista, es en la ciudad donde de manera más cruda interactúan estas nociones para producir pobreza y discriminación, sumándole a todo un cuarto elemento que es el de ser migrante. Esto tiene que ver con la fundación de nuestras ciudades, hecho característico de la colonia, puesto que se construyeron como afirmación del mundo europeo en América y por lo mismo se convirtieron en el símbolo de "la modernidad" en contraposición al supuesto "arcaico" mundo rural de los indígenas. Las ciudades latinoamericanas nacieron como una negación de la cultura originaria y por ello mismo terminaron cumpliendo la función de fortines militares, pues dentro de su "cerco" vivían los conquistadores a salvo no sólo de los levantamientos indígenas sino también bajo los privilegios y beneficios de la estructura social creada por la colonia. Resultado de ello, lo rural en América Latina es equivalente de indígena y lo urbano de occidental. Por ello no hay espacio mejor para sentir el peso de la discriminación, para que el o la indígena, se convierta en ajeno, migrante, que cuando habita la ciudades (CEDIB, 2009, s/p).

Queda clara la visión y mirada social de la organización, sin embargo, en este intento por visibilizar estas desigualdades sociales, existe la tendencia hacia la mirada colonial. Es decir, al hablar de la mujer indígena, se agrega indiferentemente el ingrediente "pobre" 
que no es otra cosa que la estereotipación de esta identidad, un "discurso 'miserabilista' que objetiviza a indios y mujeres como víctimas sufridas, objetos de la explotación y tributarias/os de una identidad y protagonismo ajenos, logra sumirlos/as en el anonimato colectivo de su condición de colonizados/as, privándoles de su condición de sujetos protagonistas de la historia" (Rivera Cusicanqui, 2005, p. 137).

Estos modos de estereotipar a la mujer indígena nacieron justamente del pensamiento y noción occidental de representación del otro. Es decir, se produce la lógica de la monocultura del tiempo lineal, es decir, el progreso, la modernización y el crecimiento traen consigo conocimientos y por ende un nuevo orden social dominante en el cual "la modernidad occidental ha producido la no contemporaneidad de lo contemporáneo" (de Sousa Santos, 2010a, p. 22). O más bien, a decir de Rivera Cusicanqui, se crean los estereotipos del indígena proveniente del área rural con rasgos étnicos marcados e incapaces de ser parte de una sociedad moderna, reproduciendo así una alteridad teatral de los pueblos indígenas. Pues en un intento de reivindicación de los pueblos originarios se remite directamente a,

(...) hablar de pueblos situados en el 'origen', se niega la coetaneidad de estas poblaciones y se las excluye de las lides de la modernidad. Se les otorga un status residual, y de hecho, se las convierte en minorías encasilladas en estereotipos indigenistas del buen salvaje guardián de la naturaleza (2010a, p. 59)

Pues al hablar de migración, se niega la pertenencia de estas identidades a la denominada ciudad. Se establece entonces, una división imaginaria entre la ciudad y lo rural, el centro y la periferia, norte y sur, creándose una brecha entre dos mundos que son iguales pero no son lo mismo. Esto produce, a decir de Bhabha, el mimetismo colonial que,

(...) es el deseo de un Otro reformado, reconocible, como sujeto de una diferencia que es casi lo mismo pero no exactamente. (...) signo de lo inapropiado, una diferencia u obstinación que cohesiona la función estratégica dominante del poder colonial, intensifica la vigilancia, y proyecta una amenaza inmanente tanto sobre el saber 'normalizado' como sobre los poderes disciplinarios (2002, p. 112, las cursivas del autor).

En este sentido, es posible entender cómo el imaginario colonial ha establecido sus raíces dentro de la sociedad boliviana, pues en los intentos de quebrantar con la lógica de las diferencias, el discurso surge a partir de las lógicas occidentales de pensamiento. Esto, ha sido difícil -y sigue siendo-, de modificar en la sociedad boliviana, y es que, en los intentos más críticos de visibilizar la desigualdad y revalorizar la diferencia, se ha caído sigilosamente en la reproducción del pensamiento colonial.

Ahora bien, la publicación del CEDIB simplemente revela la mirada de bolivianos representando a bolivianos. Es decir, la organización no es autora de las imágenes que representan a la mujer indígena.

Si bien la temática está fuertemente delimitada y enmarcada en esta migración mencionada, es cierto que también proponen la exposición de diversidad de percepciones y miradas. 
Esta propuesta, surge de cuestionamientos como: ¿Cuál es el significado de ser indígena en la ciudad? ¿Qué miradas existen, persisten o se renuevan? (CEDIB, 2009).

En este sentido, la organización plantea descubrir el tipo de miradas existentes en la sociedad, por lo tanto, no pretende analizarlas, sino simplemente exponerlas.

Es pues entonces, el objetivo de este artículo llegar un poco más lejos con estas imágenes, para dar cuenta del discurso y la mirada estereotipada y colonial fuertemente anclada en la sociedad boliviana, a pesar de haber atravesado un cambio tan profundo a nivel político y social.

\section{El discurso visual de lo social}

Se entiende que la fotografía es una interpretación del mundo (Sontag, 2006), puesto que la intencionalidad de cada imagen transmite un discurso en tanto se enmarca en un contexto social y cultural. Un discurso visual que supone una decisión ante un momento determinado que valía la pena ser capturado por el ojo de la cámara.

Esta interpretación, se traduce en signos que actúan como fuerzas sociales (Eco, 1986). Es decir, "las cosas solamente eran conocidas por medio de las unidades culturales que el universo de la comunicación hacía circular en lugar de las cosas" (Eco, 1986, p. 59, las cursivas el autor).

Toda la interpretación que los seres humanos tienen del mundo proviene de las unidades culturales, por lo tanto, los signos son fuerzas sociales en tanto transmiten imaginarios, ideologías, pensamientos, sentimientos humanos, etc.

Estos signos, son el objeto de estudio del presente capítulo, ya que han sido elegidos de manera objetiva y subjetiva de entre las múltiples opciones de los elementos visuales.

El análisis fotográfico, entonces, se aborda a partir de comprender que las imágenes se encuentran en un contexto, esto supone que

(...) una imagen puede adquirir innumerables interpretaciones o significados según los diferentes códigos y referentes que diversos observadores ponen en ella. Si bien las ideologías existentes sobre género y raza limitan en forma efectiva el rango de interpretaciones que se aplican a un retrato fotográfico, la "significación" de esa fotografía no puede controlarse en el sentido de que su imagen (significante) permanece vinculada a algún código o referente (significado) determinado (Poole, 2000, p. 29).

En definitiva, las imágenes del catálogo "Mujer indígena en la ciudad", están vinculadas a estos códigos o referentes coloniales mencionados anteriormente, pues, todos los referentes sociales que marcaron la miradas de los autores que permanece en la fotografía dándole el sentido o la significación, proviene de una sociedad anclada en hechos de dominación y exclusión de las sociedades indígenas y en mayor medida, de la mujer.

El referente o significado, no es otra cosa que la construcción cultural de las cosas, es decir, los códigos a partir de los cuales se dan sentido al significante -la imagen-, que provienen 
de las unidades culturales que determinan la entidad abstracta de este referente, por lo tanto, funciona como fenómeno social (Eco, 1986).

Para realizar la decodificación del significante en las imágenes, es necesario entender el concepto de análisis estructural de la imagen que propone Barthes (1992), en tanto la imagen -fotográfica-, cargada de historia cultural y social del entorno de la cual proviene, resulta de una reducción de la realidad a partir de la representación de un determinado momento y en determinado tiempo. Esta reducción que pretende ser literal, pasa por distintas técnicas de encuadre, perspectiva, color, entre otras, intentando mostrar fielmente una realidad, por lo tanto, no existe la transformación de dicha realidad. Sin embargo, por más análogo que pretenda ser el mensaje fotográfico, la connotación del mismo sigue presente por el hecho de pertenecer a una opinión e interpretación socialmente enmarcada. En este sentido, la fotografía presenta dos tipos de mensaje, uno con código, que pretende ser la representación fiel de la realidad, y paradójicamente, el mensaje sin código, que atraviesa la connotación inconsciente de una fotografía asediada por los valores de la sociedad, pues "el código del sistema connotado está constituido visiblemente bien por su sistema de símbolos universal, bien por una retórica de una época, en definitiva, por una reserva de estereotipos (esquemas, colores, grafismos, gestos, expresiones, agrupaciones de elementos)" (Barthes, 1992, p. 14).

Para entender el discurso atravesado por el ojo colonial y entender el mensaje connotado dentro de las imágenes, se analizan las fotografías más representativas del catálogo, es decir las imágenes con mayor carga discursiva visual y textual.

\section{La revalorización como forma de reproducción}

Como se mencionó anteriormente, "Mujer indígena en la ciudad" cuenta con imágenes pertenecientes a diversos autores. Es decir, diversas formas de ver y representar al mundo, pero que, desde su análisis, comparten un discurso similar. A continuación, se analizan algunas de estas fotografías, como muestra de un discurso colonial anclado en el imaginario boliviano.

Los títulos de las imágenes corresponden a los autores de las mismas y forman parte de este discurso sobre la mujer indígena. 


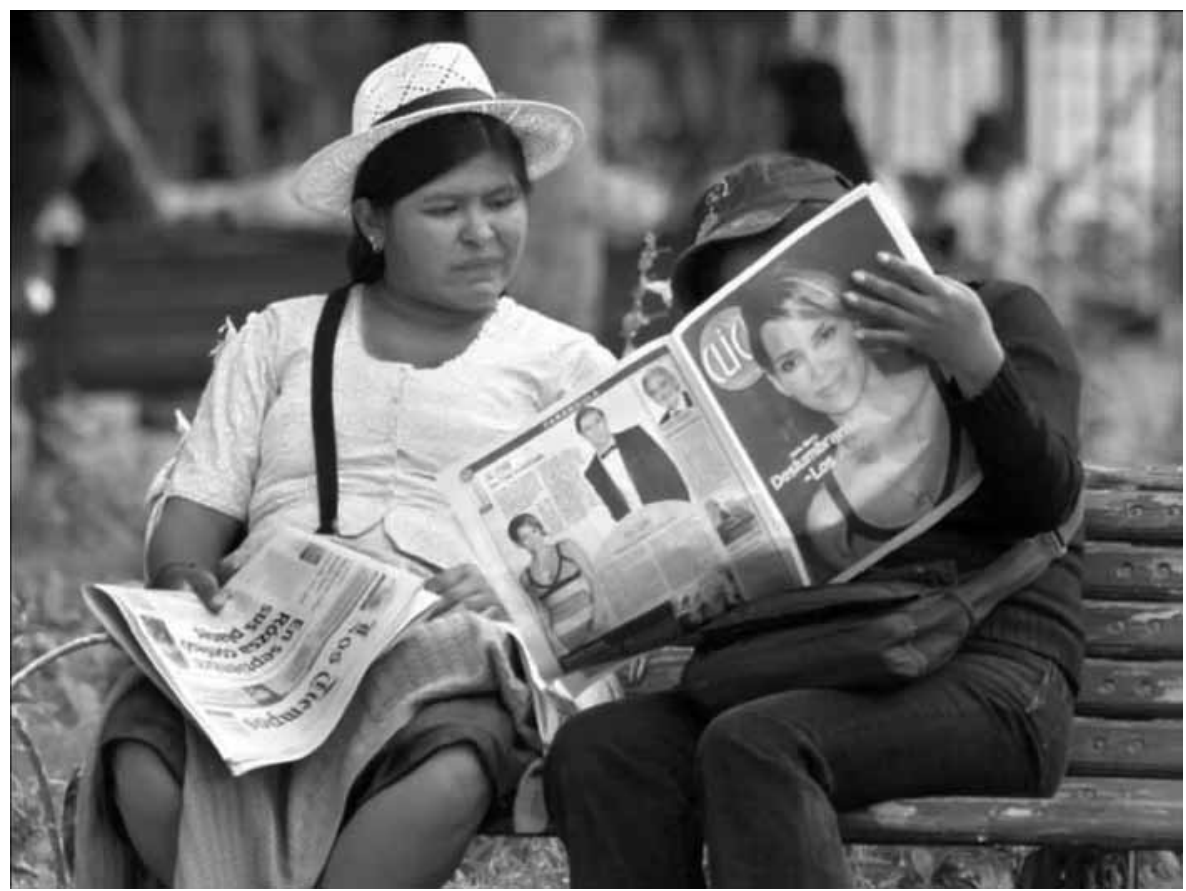

Figura 1. Intercambiando rostros. Fuente: Elsa Norka Velasco López, en CEDIB, 2009.

Esta imagen pertenece a la categoría de fotografía pura dentro del catálogo. Es decir, no contiene ningún retoque digital o manual. Sin embargo, el mensaje connotado está presente. El título, intercambiando caras, designa una especie de deseo de pertenencia. El intercambio de caras es producido por la portada de la revista o periódico que una de las mujeres sostiene y que, efectivamente, le cubre el rostro para ser reemplazado con el de la modelo.

Esta imagen contiene signos culturales fuertemente instaurados en la sociedad. Pues representa objetos que actúan como unidades de connotación que:

(...) son inductores habituales de asociaciones de ideas Estos objetos constituyen excelentes elementos de significación: por una parte, son discontinuos y completos en sí mismos, lo cual constituye una cualidad física para un signo; por otra, remiten a significados claros, conocidos; son los elementas de un auténtico léxico, tan estables que se les podría dar una estructura sintáctica con facilidad (Barthes, 1992, p. 18-19). 
Por su parte, la significación determina la relación entre el significante y el significado. Es decir, los códigos de connotación construidos cultural y socialmente, se traducen en signos de diversos tipos que se enuncian a través de gestos, actitudes, expresiones, etc., y a partir de un acuerdo social e histórico de cómo debe darse sentido a estas enunciaciones. Por lo tanto, la significación será el resultado de la asociación de ese signo con su sentido social y cultural en tanto mensaje (Barthes, 1992).

Los signos, pueden ser divididos entre naturales y artificiales. Los primeros pertenecientes a suceso relativos a la naturaleza o a acciones involuntarias e inconscientes del ser humano. Los segundos, producidos específicamente para significar por un lado, y por otro, como funciones primarias o secundarias de la cultura y a partir de las cuales se establecen las relaciones sociales como por ejemplo la vestimenta que en su función primaria cumple como cobertor o protector del cuerpo y, en su función secundaria puede determinar estatus social, oficio laboral o pertenencia cultural (Eco, 1994).

En el caso de la Figura 1, existe este código natural cultural que establece una dicotomía entre ambas mujeres. La mujer de pollera, es decir la chola, es representada en su totalidad, con el rostro expuesto. Como se mencionó anteriormente, la imagen de la chola era percibida como la identidad indígena que cambió su vestimenta y la adaptó a las del conquistador para pertenecer a la ciudad y que, actualmente tiene connotaciones negativas dentro de las clases altas y hegemónicas del país.

Entonces, por un lado la representación de la mujer chola, que es signo de lo indígena y de ese mestizaje a partir de su vestimenta, se contrapone a la mujer con el rostro reemplazado por una modelo occidental. A esta mujer, a quien se le ha dado el título de "intercambiando caras" y representada por signos culturales en la vestimenta occidentalizada, se le ha quitado la identidad indígena que en la ciudad se supone se transforma.

Por otro lado, la imagen no representa ninguna característica o signo que defina a la ciudad. Es decir, el encuadre y el desenfoque de fondo, no permiten establecer una relación entre el sujeto y el escenario de ciudad que supuestamente define la temática y es pues, en ese sentido, que la imagen define la pertenencia de la mujer indígena en la ciudad a partir de objetos culturales estereotipados como el periódico, signo de lectura y nivel de educación y el pantalón, como signo de vestimenta anclada en la modernidad occidental. Del mismo modo, la siguiente imagen representa ese deseo o mimetización mencionado anteriormente, que se le ha atribuido al indígena. En este caso, se hace énfasis en la categoría de blanquitud como signo de superioridad representado por la muñeca norteamericana.

Con la tez blanca, los ojos azules y el poco cabello rubio que se puede ver, esta muñeca -que a su vez representa la figura de la mujer occidental-, sobresale por el completo desenfoque de la mujer indígena que resulta casi una mancha en la imagen. ¿Por qué mujer oculta? ¿De qué se oculta la mujer indígena? ¿Por qué está representada como fondo de la imagen, muy por detrás de la muñeca?

La connotación de la imagen es un tanto alarmante, pues mantiene el discurso de superioridad anclado en la raza y el color de la piel de las personas. Por otro lado, al representar a la mujer indígena con un desenfoque total con una intención de ocultarse -que nace a partir del texto-, de la mirada, del exterior, del ojo, del mundo, por detrás de la mujer blanca, resultando no en otra cosa que la inferiorización de la identidad ya no sólo del indígena, sino nacional, por sobre las europeas o americanas, en este caso. 
Y es que acaso, dentro de este discurso, ¿la mujer indígena en la ciudad tiende a ocultarse detrás de la occidental? ¿o es más bien un intento por demostrar ciertas aspiración? Lo que resalta hasta cierto punto es la comparación, una dicotomía entre el concepto de raza y el concepto de ciudadano.

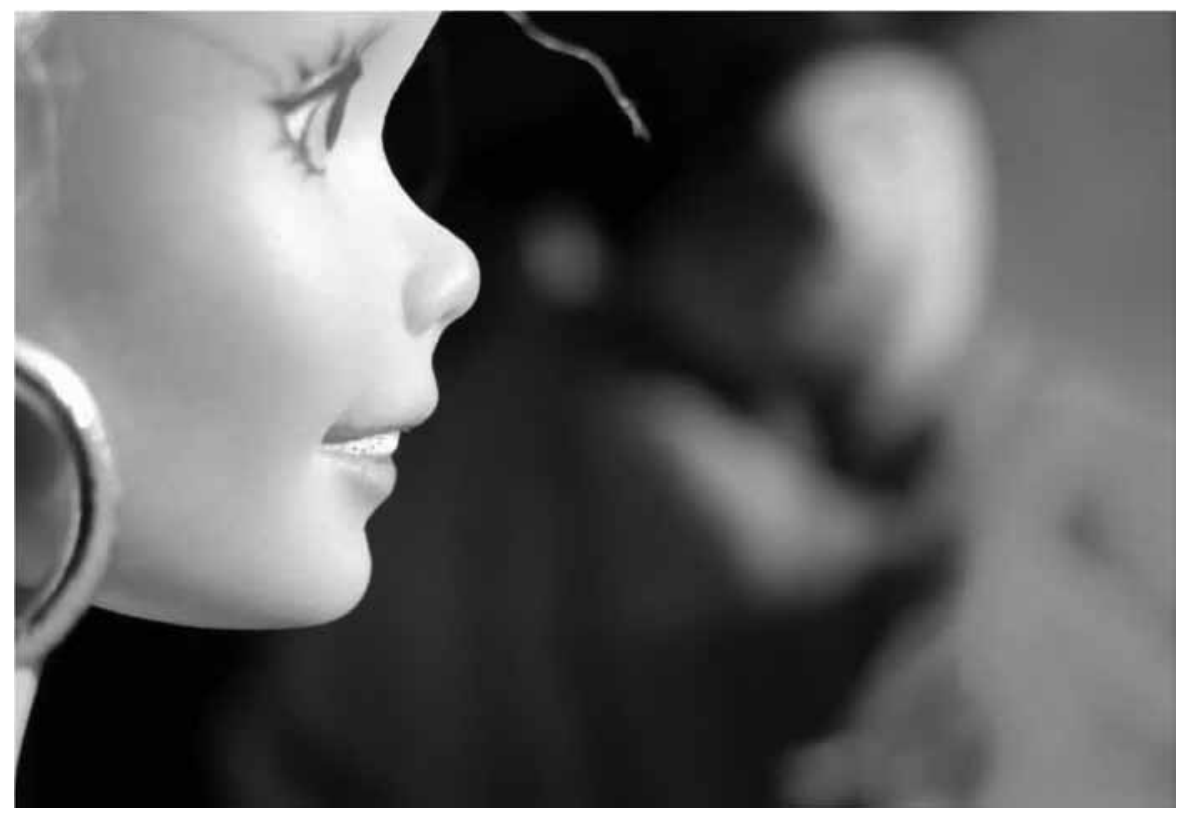

Figura 2. Mujer oculta. Fuente: Dafne Noemí Argandoña Tellería, en CEDIB, 2009.

En este sentido, la figura de la mujer indígena en la ciudad representada en la imagen 2, resulta de un discurso enmarcado en la sociología de las ausencias propuesta por Boaventura de Sousa Santos, que se determina la invisibilización de todo aquello que la lógica eurocéntrica ha denominado como no existente. Es decir,

(...) la no existencia es producida siempre que una cierta entidad es descalificada y considerada invisible, no inteligible o desechable. No hay por eso una sola manera de producir ausencia, sino varias. Lo que las une es una misma racionalidad monocultural. [Se distinguen] cinco modos de producción de ausencia o no existencia: el ignorante, el retrasado, el inferior, el local o particular y el improductivo o estéril (de Sousa Santos, 2010a, p. 22). 
Pues si bien la temática propuesta por el CEDIB es la visibilización y los modos de representación de la mujer indígena, lo que hace esta imagen es justamente adentrarse en la lógica de producción de la no existencia. Y, al mismo tiempo, se adscribe bajo la forma de la primera lógica de producción de las ausencias, la del ignorante.

Esta ausencia deriva de la monocultura del saber, que "consiste en la transformación de la ciencia moderna y de la alta cultura en criterios únicos de verdad y de cualidad estética, respectivamente" (de Sousa Santos, 2010a, p. 22). En este sentido, la no existencia nace tomando la forma de ignorancia o de incultura.

La monocultura del saber, logra complementarse con el concepto de "geopolítica del conocimiento" de Mignolo (2013), que se refiere a una modernidad en la que surgen los escenarios de exclusión, diferencias raciales enmarcadas por los estereotipos coloniales de blanquitud igual a progreso y supremacía.

La imagen de la "mujer oculta" se encuentra dentro de la categoría "identidad" en el catálogo de las fotografías. ¿Cuál es entonces la identidad aquí representada? Lo que sucede es que se mira una identidad a partir de la comparación con otra, es decir, se representa el discurso de la otredad. Por lo tanto, la identidad representada no se define por lo que es, sino más bien por lo que no es. Esto sucede en tanto el discurso dominante ha establecido esa alteridad, la diferencia de un nosotros frente a los otros (Appadurai, 2007).

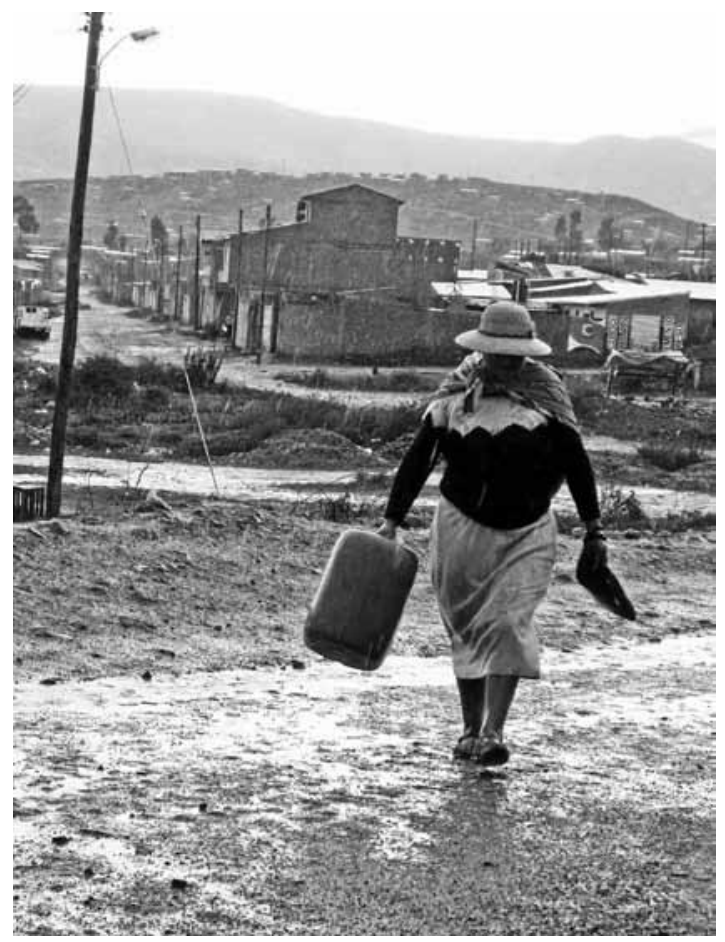

Figura 3. Al norte esta el barrio más rico. Fuente: Fátima Bernal Martinez, en CEDIB, 2009. 
Esta imagen se encuentra ubicada en la categoría "ciudad" del libro. Esta fotografía representa aquella división norte-sur mencionada en páginas anteriores.

La realidad de las ciudades bolivianas es ciertamente dividida por una brecha imaginaria que no sólo se delinea en las clases sociales, sino también contiene contrastes importantes tanto estructurales como económicamente entre el centro y la periferia.

Esta imagen entonces, representa este contraste, pero al hacerlo se sume en el discurso colonial esteriotipando al indígena bajo el concepto de "miserabilismo" utilizado por Rivera Cusicanqui, que establece que "la noción de miseria, al igual que la más moderna de pobreza, despojan a los actores populares (indígenas, mujeres, trabajadores) de su condición de sujetos de la historia" (Rivera Cusicanqui, 2005, p. 134).

$\mathrm{Al}$ representar al indígena sumergido en estereotipos tales como el pobre y enajenado en tanto no pertenece "al barrio más rico", se logra justamente reproducir los modos de subordinación anclados en la generalización de un grupo social tan diverso.

Esta mirada establece nuevamente el discurso de alteridad, pues el título "al norte está el barrio más rico" establece su comparación y al hacerlo, simula la voz del subalterno. En este sentido, surge la representación en tanto sustitución, es decir, la voz del dominante habla por aquel subalterno que no tiene voz (Spivak, 2011).

En el caso de las fotografías expuestas y en muchas más encontradas en el libro publicado, esta sustitución se produce constantemente en el sentido de revalorizar, hablar por. Esto no significa que no deba o pueda hacerse en tanto se tenga conciencia crítica respecto a la identidad que se representa y sobre todo hacerlo con una mirada despojada del imaginario colonial que se ha impuesto, pues ¿qué pasaría si estas mujeres representadas contaran su historia? ¿Su visión de ciudad y su papel dentro de la misma estaría representada de esta manera?

\section{Conclusiones}

El discurso visual sobre la mujer indígena boliviana contiene fuertes rastros del imaginario colonial heredado. Pese a los intentos de reivindicación y revalorización de estas identidades, la mirada con la que se han diseñado las imágenes contiene una carga importante de un discurso hegemónico occidental anclado en los estereotipos sociales definidos por categorías tales como la raza, el color de piel y el poder económico, y los signos establecidos culturalmente han permitido encasillar a un grupo social tan diverso dentro de un solo concepto: el subalterno.

Estos estereotipos, suponen una mirada colonial en tanto se delimita su quehacer, se asumen sus deseos y anhelos y, se le impone un rol dentro de la ciudad. Un rol que, por supuesto, presupone una participación escasa y excluida de la sociedad.

En este sentido, se sigue la lógica de la alteridad, pues mientras se siga viendo al indígena o a la mujer indígena como un otro antagónico, como el diferente para establecer el propio yo y por lo tanto, el nosotros frente a los otros, no se podrá establecer un discurso que rompa con el pensamiento colonial. 
En tanto se mire a través de este ojo, se seguirán reproduciendo los modos de dominación y subordinación que se pretende evidenciar. Es justamente este intento de revalorización el que ha generado la necesidad de hablar por este sujeto.

Asumir y sustituir la voz de aquel al que se le ha atribuido y generalizado la subalternidad, es simplemente ejercer el poder por sobre el mismo.

\section{Referencias Bibliográficas}

Appadurai, A. (2007). El rechazo de las minorías. Ensayo sobre la geografía de la furia. Barcelona: Tusquets Editores.

Barthes, R. (1992). Lo obvio y lo obtuso. Imágenes, gestos, voces. Barcelona: Paidós.

Bhabha, H. (2002). El lugar de la cultura. Buenos Aires: Manantial.

Bonfil, G. (1972). "El concepto del indio en América: Una categoría de la situación colonial”. Anales de Antropología. IX(1), 105-124.

Bourdieu, P. (2003). Un arte medio. Ensayo sobre los usos sociales de la fotografía. Barcelona: Gustavo Gili.

De Sousa Santos, B. (2010a). Descolonizar el saber. Reinventar el poder. Montevideo: Trilce. Eco, U. (1986). La estructura ausente. Introducción a la semiótica. Barcelona: Lumen. . (1994). Signo. Colombia: Letra E.

Dubois, P. (1986). El acto fotográfico. De la representación a la recepción. Barcelona: Paidós. González Casanova, P (s/f). "Colonialismo Interno (una redefinición)”, [en línea]. Universidad Nacional Autónoma de México. Instituto de Investigaciones Sociales. Recuperado de http://conceptos.sociales.unam.mx/conceptos_final/412trabajo.pdf [06 de junio de 2018].

Hopenhayn, M. (1999). "La aldea global entre la utopía transcultural y el ratio mercantil”. En I. Degregori, G. Portocarrero (Ed.) Cultura y globalización (pp. 17-36). Recuperado de: http://globalsolidarity.antenna.nl/hopenhayn.html [4 de junio de 2017].

Mignolo, W. (2013). "Geopolítica de la sensibilidad y del conocimiento. Sobre (de) colonialidad, pensamiento fronterizo y desobediencia epistémica”. Revista de Filosofía, 2(74) 7-23. Recuperado de: http://produccioncientificaluz.org/index.php/filosofia/article/ view/18261/18249 [28 de mayo de 2017].

Poole, D. (2000). Visión, raza y modernidad. Una economía visual del mundo andino de las imágenes. Lima: Sur Casa de Estudios del Socialismo.

Rivera Cusicanqui, S. (2010a). Violencias (re) encubiertas en Bolivia. La Paz: La Mirada Salvaje.

. (2010b). Ch'ixinakax utxiwa. Una reflexión sobre prácticas y discursos descolonizadores. Buenos Aires: Tinta Limón.

. (2005). "Construcción de imágenes de indios y mujeres en la iconografía post 52: el miserabilismo en el Álbum de la Revolución”. T’inkazos. Revista Boliviana de Ciencias Sociales, (19) 133-156. Recuperado de http://www.redalyc.org/articulo. oa?id=426141562008 [27 de abril de 2017].

Sontag, S. (2006). Sobre la fotografía. Madrid: Alfaguara.

Spivak, G. (2011). ¿Puede hablar el subalterno? Buenos Aires: El cuenco de plata. 
Todorov, T. (1990). El cruce de las culturas (Trad. D. Navarro). Criterios 25(28), 3-19. Recuperado de: http://www.criterios.es/pdf/I371todorov.pdf [26 de mayo de 2017].

Verón, E. (1993): La semiosis social. Fragmentos de una teoría de la discursividad. Barcelona: Gedisa.

Zegada, M. (2012): Indígenas y mujeres en la democracia electoral. Análisis comparado. México D.F.: Tribunal Electoral del Poder Judicial de la Federación.

\title{
Fuente Primaria
}

CEDIB. (2009). Concurso Nacional de Fotografía. Mujer indígena en la ciudad. La Paz: CEDIB.

\begin{abstract}
The present article will address the design of the visual discourse of the photographs published in the book Mujer indigena en la ciudad made by the Documentation and Information Center of Bolivia. The objective is to analyze the discourse on indigenous women and their role in the city; that is, how society has designed a visual discourse that represents the identity of the indigenous woman with colonial characteristics. It is, then, through these photographs that one can understand the rooting of the imaginary and the colonial vision in societies that have been conquered and that keep in their gaze the ways of identifying and defining the other.
\end{abstract}

Keywords: Visual discourse - Image design - Identity - Alterity - Other.

Resumo: O presente artigo abordará o desenho do discurso visual das fotografias publicadas no livro Mujer indígena en la ciudad elaborado pelo Centro de Documentação e Informação da Bolívia. O objetivo é analisar o discurso sobre as mulheres indígenas e seu papel na cidade; isto é, como a sociedade desenhou um discurso visual que representa a identidade da mulher indígena com características coloniais. E, por conseguinte, através destas fotografias, que pode-se compreender o arraigamento do imaginário e a visão colonial nas sociedades que foram conquistadas e que êles mantêm em seus olhares os modos de indetificar e definir ao outro.

Palavras chave: Discurso visual - Design de imagen - Identidade - Alteridade - Outro.

[Las traducciones de los abstracts fueron supervisadas por el autor de cada artículo] 